\title{
Gelatin Zymography
}

National Cancer Institute

\section{Source}

National Cancer Institute. Gelatin Zymography. NCI Thesaurus. Code C19835.

An SDS-PAGE based procedure used to identify matrix metalloproteinases. 